\title{
Effect of Dobutamine on Adenylate Cyclase Activity in Rabbit Renal Pelvis and Ureter
}

\author{
Shun Kondo, Takashi Morita, Seigi Tsuchida, Miyuki \\ Terui* and Yohtalou Tashima* \\ Department of Urology, and *the Second Department of \\ Biochemistry, Akita University School of Meidicine, Akita \\ 010
}

Kondo, S., Morita, T., Tsuchida, S., Terui, M. and Tashima, Y. Effect of Dobutamine on Adenylate Cyclase Activity in Rabbit Renal Pelvis and Ureter. 1986, 148 (1), 113-114_ The adenylate cyclase activity in the rabbit renal pelvis and ureter was measured by the method of Salomon et al. (1974). The dobutamine-induced increase of adenylate cyclase activity is more prominent in the renal pelvis including the pacemaker region than in the ureter that is nonpacemaker region in the upper urinary tract. Therefore, it is thought that the pacemaker region is different from other regions in the upper urinary tract with regard to responses to dobutamine.—— adenylate cyclase activity; $( \pm)$ dobutmine; pacemaker of ureteral peristalsis

It has been reported that the pacemaker of ureteral peristalsis exists at the pelvicalyceal region in the upper urinary tract, while, the nature of the pacemaker of ureteral peristalsis remains unknown. We found that the pacemaker activity was promoted by dobutamine in the electromyographic study (Morita and Suzuki 1984). In the present study, we investigated the action of dobutamine on the adenylate cyclase activity in the rabbit renal pelvis and ureter in order to elucidate whether or not the generation of cyclic AMP is involved in the action of dobutamine on the upper urinary tract.

Two adult Japanese white rabbits (body weight $3 \mathrm{~kg}$ ) were immobilized by intravenous administration of pancuronium bromide $(0.1 \mathrm{mg} / \mathrm{kg})$. Bilateral kidneys and ureters were excised as quickly as possible after immobilization. The kidney and ureter were placed in cold $0.9 \% \mathrm{NaCl}$ solution and dissected into pelvis and ureter specimens, removing the renal parenchyma, vessels and fat tissue carefully. The cell membrane preparation was obtained from specimens and the adenylate cyclase activity was determined according to the method of Salomon et al. (1974). Briefly, the adenylate cyclase activity of the cell membrane was determined by assessing the rate of breakdown of ${ }^{32} \mathrm{P}$-cAMP into ${ }^{32} \mathrm{P}$-cAMP in the incubation mixture. The ${ }^{32} \mathrm{P}$-cAMP generated from the ${ }^{32} \mathrm{P}-\mathrm{ATP}$ was separated by application of column chromatography using the Dowex ${ }^{\circledR}$ cation exchange resin and the neutral alumina. Then, the radioactivity of ${ }^{32} \mathrm{P}$-cAMP was measured with a liquid scintillation counter. The adenylate cyclase activity was expressed as the amount of cAMP generated from ATP, pmoles of $\mathrm{cAMP} / \mathrm{mg}$ protein $-\mathrm{min}$. The statistical significance of the results was evaluated by Student's $t$-test for paired samples. A $p$ value of less than 0.05 was considered to be

Received January 23, 1985; accepted for publication October 25, 1985.

Director: Prof. S. Tsuchida and Prof. Y. Tashima. 
TABLE 1. Adenylate cyclase activity in rabbit upper urinary tract

\begin{tabular}{lll}
\hline & Renal pelvis & Ureter \\
\hline Basal & $0.819 \pm 0.019$ & $1.019 \pm 0.090$ \\
$\mathrm{NaF}(20 \mathrm{mM})$ & $7.970 \pm 2.056 \dagger$ & $4.728 \pm 1.340 \ddagger$ \\
Dobutamine $10^{-6} \mathrm{M}$ & $1.382 \pm 0.218 \ddagger$ & $1.207 \pm 0.160$ \\
Dobutamine $10^{-5} \mathrm{M}$ & $1.744 \pm 0.149^{*}$ & $1.362 \pm 0.208$ \\
Dobutamine $10^{-4} \mathrm{M}$ & $1.582 \pm 0.211 \dagger$ & $1.101 \pm 0.126$ \\
\hline
\end{tabular}

$($ pmoles of $\mathrm{cAMP} / \mathrm{mg}$ protein $\cdot \min )$ mean \pm s.E. $(n=4)$

${ }^{*} p<0.001 ; \dagger p<0.02 ; \ddagger p<0.05$ vs basal.

$\mathrm{NaF}$-induced increase in adenylate cyclase activity is significant in both renal pelvis and ureter.

Dobutamine-induced increase in adenylate cyclase activity is significant only in renal pelvis, while, in ureter, not significant.

significant. $( \pm)$-Dobutamine was used in the present study.

The adenylate cyclase activities obtained from the rabbit renal pelvis and ureter are shown in Table 1. NaF increased the adenylate cyclase activity in both the renal pelvis and the ureter markedly from the respective basal values. Dobutamine increased significantly the adenylate cyclase activity in the renal pelvis, while in the ureter it increased the activity slightly but not significantly.

Therefore, the renal pelvis including the pacemaker region is thought to be different from other regions in the upper urinary tract with regard to the response to dobutamine. It is not clear in the present study which subtypes of $\beta$-receptors, $\beta_{1}^{-}$, or $\beta_{2}-$, are responsible for increase in adenylate cyclase activity produced by dobutamine (Ruffolo and Yaden 1983).

\section{References}

1) Morita, T. \& Suzuki T. (1984) Effects of $\beta$-adrenergic agonists on the pacemaker of ureteral peristalsis. Urol. int., 39, 154-158.

2) Ruffolo, R.R., Jr. \& Yaden, E.L. (1983) Vascular effects of the stereoisomers of dobutamine. J. Pharmacol. exp. Ther., 224, 46-50.

3) Salomon, Y., Londos, C. \& Rodbell, M. (1974) A highly sensitive adenylate cyclase assay. Analyt. Biochem., 58, 541-548. 